\title{
Motivational Interviewing Training Using Role Play in Dental Hygiene Students
}

\author{
Ye Seul $\mathrm{Han}^{\dagger}$ and Young Sik Cho \\ Department of Dental Hygiene, The Graduate School of Namseoul University, Cheonan 31020, Korea
}

The purpose of this study was to develop a motivational interviewing (MI) training program to improve competency in communication and to effect the evaluated changes that would occur in dental students' counseling techniques as result of the training in the program. The study proceeded through the program via role-play practice, which was explained effectively during the Ml program training process. A convenience sample of 43 fourth-year dental hygiene students was recruited. Twenty-two students were randomly assigned to the intervention group and 21 to the control group in the order of recruitment. The theoretical lecture was delivered over 3 hours and the practice was done in parallel by applying cases occurring in clinic settings. The practice was technical training, partner practice, and small group practice. The intervention group received three hour Ml lecture while the control group received no lecture. Evaluation through role-play practice was separated according to "researcher's viewpoint," "counselor's role viewpoint," and "patient's role viewpoint." The results of the analysis showed that the intervention group had higher Ml skills and ability than the control group. Furthermore, program participants showed positive impressions to the Ml training program. The use of coaching sessions improved the MI techniques and counseling skills of dental hygiene students learning MI. The effect of the application of the MI training program was that the $\mathrm{Ml}$ training improved counseling skills and interviewing abilities. Moreover, continuous training and feedback enhanced Ml techniques and core skills. Training using lectures in parallel with practice rather than education through theory alone improved students' techniques. Application of role play through the combined method of the Ml program was confirmed by an effective training method.

Key Words: Communication, Motivational interviewing, Role play

\section{Introduction}

According to the Report on the Basic Vocational Skills Standards Development by the Human Resources Development Service of Korea ${ }^{1)}$, communication is mandatorily included as a basic vocational skill that is emphasized by the workspace. According to the National Skills Standard of the United States, the basic vocational skills include communication skills of reading, writing, listening, and speaking; the National Occupational Standard of the United Kingdom and the Australian Standard Framework also lists communication competence as a critical duty as one of its lower units.

In the dental industry, communication competence is an important skill used in increasing patient satisfaction and quality of care. The American Dental Hygienists Association $^{2)}$ and the Commission on Dental Accreditation ${ }^{3)}$ both emphasize effective communication in the standard competencies of dental hygienists, and propose to include communication education in their curricula.

In Korea, the National Competency Standard (NCS) was developed in 2002, and competency-based education is provided at higher education levels ${ }^{1}$. Recently, the dental hygiene industry has also introduced classes on communication, differing significantly from the subjects of dentistry or dental hygiene in an effort to cultivate competencies that can be used in the field. Ryu et al. ${ }^{4)}$ reported that Korean dental hygiene students have a strong

It reconstruct the first author's doctoral thesis in this paper. 
need for communication classes; a study by Choi et al. ${ }^{5)}$ presented the need for regular curricula to cover communication improvement within college education.

To obtain results on communication abilities, it is important to secure methods of acquiring knowledge and attitude in the cognitive and affective domains. Bazata et al. ${ }^{6}$ explained that health education that results in individual behavioral changes does not simply involve providing advice or recommendations. As such, studies have reported the effectiveness of patient-centric education systems to transfer knowledge on oral health management ${ }^{7-10)}$. Motivational interviewing (MI), receiving spotlight in the dental industries, is a counseling method that centers on the interviewee, and has been introduced as a method that utilizes multiple techniques to explore the inner mind of the interviewee and induce behavioral changes ${ }^{11)}$. From the early 2000s, MI was introduced to the dental industry, and has become an independent system since $2012^{12)}$. Rollnick et al. ${ }^{13)}$ experimented with the application of a brief MI from the health aspects to be applied to the clinical field. While MI began to be explored in the context of addiction, its potential for dental applications were explored, and the United States now includes MI in the curricula and textbooks on dentistry ${ }^{14,15)}$. According to Koerber et al. ${ }^{7)}$, and Hinz ${ }^{16)}$, MI training intervention was found to be effective in advancing interview skills. Woelber et al. ${ }^{10)}$ conducted MI training for 8 hours with dentistry college students and asked them to manage periodontal patients, and found that participants with MI training had higher interdental hygiene effects.

The training of the MI method must comprise not only lecture-style knowledge transfers, but also wide-ranging experiential opportunities to practice the techniques of interviews and attitudes of interviewers. According to Lane and Rollnick ${ }^{17)}$, maximizing the efficiency of MI education intervention required the coupling of theory lectures as well as experience of practice. Particularly, in the field of communication, training methods can include standardized patients and role-play; while the standardized patients training can recreate a real scenario, thus improving task skills, the two did not differ much ${ }^{17}$. Moreover, given similar levels of effects, it was reported that it would be clinically more efficient to employ role-play, given its potential for reducing costs and easy applications. Therefore, role-play practice is often employed in clinical studies as it is easy to apply ${ }^{8,18)}$.

Given that there have been spotlights on the communication competency training, it is necessary to provide such training at the college level. As such, this study aimed to apply the principle of MI training on dental hygiene, without its application to any other models. Moreover, this study aimed to apply the MI training program for dental hygiene students to assess its effects.

\section{Materials and Methods}

\section{Study subjects}

The subjects of this study were fourth-year college students from Namseoul Unitversity enrolled in faculties of dental hygiene. The rationale for selecting fourth-year college students was that they had completed $85 \%$ of their major courses, and they had taken the communications class, enabling them to deal with patients in hypothetical scenarios. Out of a total of 45 students, 2 were excluded as they rescinded participation or were insincere in their participation, and thus 43 students participated from May through June 2016. This study was conducted with the approval of the Institutional Review Board of Namseoul University (approval no. NSU-160630-02). To ensure that

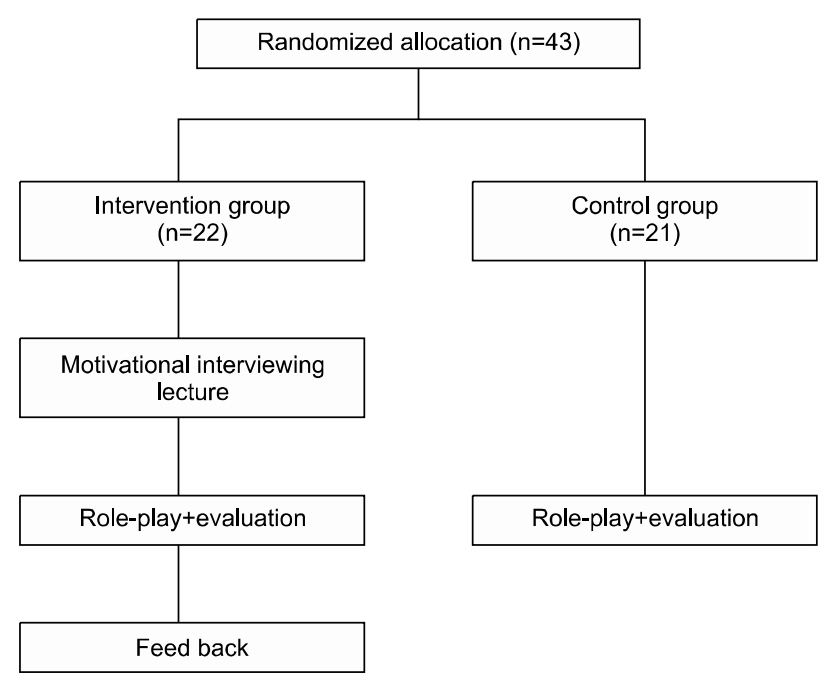

Fig. 1. Overview of procedure. 
the control group did not have any disadvantages from participating in the study, the control group was provided with the same MI training education after the completion of the experiment.

\section{Study process}

This study was designed as a part of an MI training program for dental hygiene students, where the study was composed of a section that evaluated training effects (Fig. 1). A total of 43 participants were assigned into two groups in the order of their recruitment into the study. The researcher was blindfolded during the selection. The 22 individuals in the intervention group were provided with MI training from a trained researcher. After the intervention was completed, two types of role-play were conducted to evaluate its results. Twenty-one individuals in the control group carried out the two scenarios of role-play. After the completion of the role-play, an evaluation was conducted from the perspectives of the counselor and the patient. The role-plays of the participants were recorded on video, and the researcher conducted the evaluation based on the video recordings.

\section{Training program}

The MI training program is composed of a theoretical lecture, role-play, and feedback (Table 1). The intervention group underwent role-plays after the theoretical lecture, and the control group was provided with the same lecture after the role-play to ensure that they did not have any disadvantage from participating in the study. The theoretical lecture was conducted over 3 hours, and included practices that involved the application of clinical-setting cases. The practices were divided into technique practice, partner practice, and small-group practice, and the contents of the practices were appropriately selected. The lecture was conducted by the researcher, who is a dental hygienist with MI training. The lecture was delivered using PowerPoint presentations, and the students were provided with handouts. The contents of the theoretical lecture were based on contents compiled by Wilkins ${ }^{15)}$, and was composed of MI overview, practice, emotions of both sides, change conversation, maintenance, and

Table 1. Intervention Protocol for Motivational Interviewing (MI) Training Program

\begin{tabular}{llc}
\hline \multicolumn{1}{c}{ Domain/contents } & Substance & Time (h) \\
\hline MI lecture for dental hygienist & \\
Definition of MI and brief MI & Lecture \\
Elements of the "MI spirit" & \\
Guiding principles & \\
Processes of MI & Lecture \\
MI implementation & Practice \\
Information exchange & \\
Agenda setting & \\
Core skills (OARS) & Lecture \\
Exploring ambivalence & Practice \\
Sustain talk \& change talk & \\
Decisional balance & \\
Readiness ruler & Lecture \\
Eliciting and recognizing change talk & Practice \\
Preparatory change talk & \\
Mobilizing change talk & Lecture \\
Strengthening commitment & \\
Interviewing training by role play & Role play \\
Situation 1. Parents to prevent caries in their young children & \\
Situation 2. Halitosis patients & Feedback \\
Interviewing skill feedback & Practice \\
Self-evaluation of interviewing & Discussion \\
Debriefing in small group discussion learning & \\
\hline
\end{tabular}


reinforcement. Definition of MI and brief MI focused on the explanations of the spirit, principle, and the process of MI. MI implementation included information to be exchanged during the MI process, eye contact, and core skills (OARS). Exploring ambivalence explained the change talk, maintenance talk, decision scale, and readiness scale. Eliciting and recognizing change talk explained the preparations and execution of change talk, and strengthening commitment explained reinforcement methods to maintain the change.

After the theoretical lecture was completed, role-play was conducted as a part of MI training practice to measure its effects. The role-play involved three-person teams, taking roles of the counselor, the patient, and the filmer. The first scenario of the role-play was the role of the parent of a young child at risk of cariogenicity, and the second scenario was a patient with bad breath. While the interview was conducted by individuals playing the roles of a counselor and a patient, the filmer filmed the video. The interview was kept within 10 minutes, and after the two interviews had ended for each, roles were changed, with a total of 6 interviews conducted. The role-plays took

Table 2. Brief Motivational Interviewing (MI) Training Measurement Tool

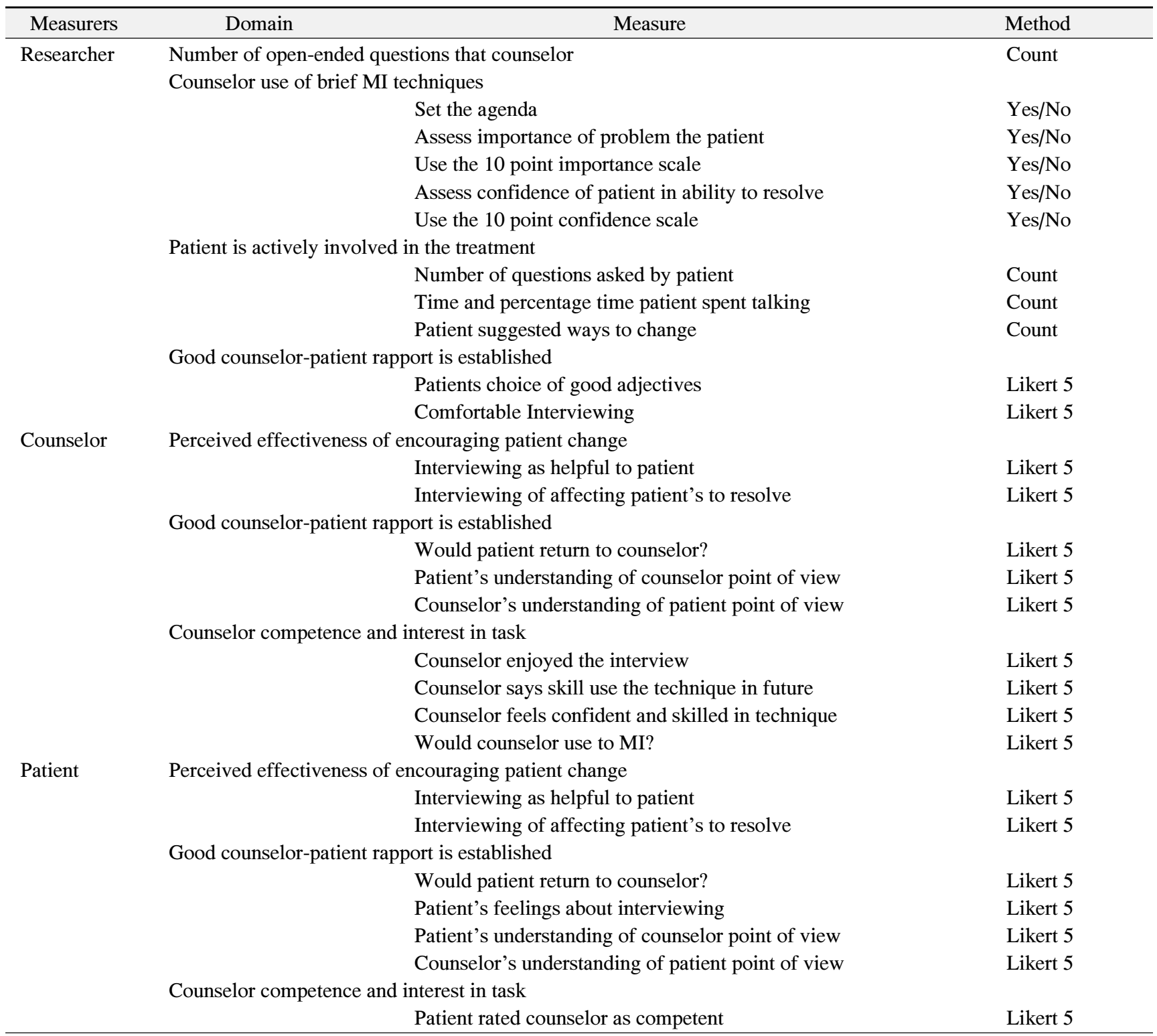


90 minutes in total. After the completion of the role-play, the brief MI evaluation scale was utilized to evaluate perspectives of the counselor and the patient. Eighty-six videos were sent to the researcher through e-mail to be evaluated from the perspective of the researcher.

After the role-play evaluations, feedback was provided using the videos. The role-play group members collectively evaluated and discussed the counseling videos. The participants were asked to analyze the distribution of core skill usage and conversation periods for self-evaluation, and the total time taken for feedback was 2 hours.

\section{Research tools}

Brief MI training measurement used by Koerber et al. ${ }^{7)}$ to evaluate dentistry students was modified and used in this study. The composition of the tool was kept the same; however, in this study it was divided by the researcher and utilized. The ratings were completed from three perspectives, which were counselor, patient, and researcher (Table 2).

\section{1) Evaluation from the researcher perspective}

The researcher perspective entailed evaluating the MI techniques, patient involvement and rapport establishment. The number of open-ended questions was quantified; MI techniques included eye contact, assessment of patient's issue, priorities, and confidence. To understand the patient responses, the number of questions asked by patient, percentage of time the patient spent talking, and the patients' suggestions to change were quantified. To confirm rapport establishment, the patients' choice of good alternatives and comfort in being interviewed were evaluated.

\section{2) Evaluation from the counselor perspective}

The counselor perspective entailed evaluating the effectiveness of encouraging patient change, rapport establishment, and counseling competence. To confirm the encouragement of patient change, the patients' responses to the counselor during the interview process was evaluated, and the relationship and understanding of the patient was reviewed for rapport establishment. To confirm the counseling competence of the counselor, the interest, technique, confidence, and intent to use MI were measured. The measurement was conducted using 5-point Likert scales.

\section{3) Evaluation from the patient perspective}

The patient perspective entailed evaluating the effectiveness of encouraging patient change, rapport establishment and counseling competence. To confirm the encouragement of change by oneself, the responses throughout the interview were evaluated, and the relationship and understanding of the counselor was reviewed for rapport establishment. The counselor's counseling competence was evaluated, and a 5-point Likert scale was used for measurement.

\section{Data analysis}

The collected data were analyzed using PASW Statistics for Windows 18.0. (IBM Co., Armonk, NY, USA) and the results from two cases per participant were averaged for the analysis. The MI skills from the MI education intervention were analyzed using chi-square goodness-of-fit test. The MI skills and competency comparisons were performed using the KolmogorovSmirnov test.

\section{Results}

\section{Evaluation of MI skills from MI training intervention}

The videos filmed were analyzed after the MI training intervention, and it was found that the intervention group utilized the majority of techniques more frequently (Table

Table 3. Motivational Interviewing (MI) Technique Evaluating Competency

\begin{tabular}{ccccc}
\hline Variable & $\begin{array}{c}\text { Intervention } \\
\text { group } \\
(\mathrm{n}=22)\end{array}$ & $\begin{array}{c}\text { Control } \\
\text { group } \\
(\mathrm{n}=21)\end{array}$ & $\chi^{2}$ & p-value \\
\hline $\begin{array}{c}\text { Brief MI techniques } \\
\text { Set the agenda }\end{array}$ & $21(95.5)$ & $21(100)$ & 39.093 & $<0.001$ \\
Assess importance & $7(31.8)$ & $0(0)$ & 49.442 & $<0.001$ \\
Use the 10 point & $5(22.7)$ & $0(0)$ & 58.930 & $<0.001$ \\
importance scale & & & & \\
Assess confidence & $15(68.2)$ & $0(0)$ & 19.581 & $<0.001$ \\
Use the 10 point & $15(68.2)$ & $0(0)$ & 19.581 & $<0.001$ \\
confidence scale & & & & \\
\hline
\end{tabular}

Values are presented as $\mathrm{n}(\%)$. 
3). The assessment items included "set the agenda," "assess importance," "use the 10-point importance scale," "assess confidence," and "use the 10-point confidence scale." More than $95 \%$ of both the intervention group $(95.5 \%)$ and the control group $(100.0 \%)$ utilized the "set the agenda" skill. In the intervention group, $31.8 \%$ conducted the "assess importance" skill; $22.7 \%$ used the "Use the 10-point importance scale" skill; 68.2\% used the "assess confidence" skill; and $68.2 \%$ used the "use the 10-point confidence scale" skill. The control group did not use any technique other than "set the agenda" and the differences between the two groups were statistically significant.

The researcher analyzed the evaluation of MI skills, and there were differences between the two groups in using open-ended questions, using brief MI techniques, and "patient suggested ways to change" among items of patient involvement and in rapport establishment (Table 4). The number of open-ended questions was higher in the intervention group $(2.43 \pm 0.73)$ versus the control group $(0.95 \pm 0.79)$, and there were statistically significant differences between the two groups. The detailed evaluation on the usage of brief MI skills by the individuals in the counselor role was quantified from 0 to 5 points,

Table 4. Evaluation of the Interviewing Technique according to the Motivational Interviewing (MI) Training Program

\begin{tabular}{|c|c|c|c|c|}
\hline Variable & Intervention group $(\mathrm{n}=22)$ & Control group $(n=21)$ & $\mathrm{Z}$ & p-value \\
\hline \multicolumn{5}{|l|}{ Evaluation from researcher's viewpoint } \\
\hline Number of open-ended question & $2.43 \pm 0.73$ & $0.95 \pm 0.79$ & 2.065 & $<0.001$ \\
\hline Use of brief MI techniques & $1.83 \pm 0.19$ & $1.00 \pm 0.00$ & 2.682 & $<0.001$ \\
\hline \multicolumn{5}{|l|}{ Patient involvement } \\
\hline Number of questions asked by patient & $1.63 \pm 1.71$ & $1.41 \pm 0.86$ & 0.851 & 0.463 \\
\hline Percentage time patient spent talking & $81.27 \pm 35.03$ & $69.95 \pm 26.84$ & 0.873 & 0.432 \\
\hline Patient suggested ways to change & $0.86 \pm 0.64$ & $0.19 \pm 0.29$ & 1.632 & 0.010 \\
\hline \multicolumn{5}{|l|}{ Rapport establishment } \\
\hline Patients choice of good adjectives & $3.96 \pm 0.67$ & $3.33 \pm 0.29$ & 2.086 & $<0.001$ \\
\hline Comfortable interviewing & $1.22 \pm 0.30$ & $1.50 \pm 0.27$ & 1.469 & 0.027 \\
\hline Total of Rapport establishment & $2.59 \pm 0.36$ & $2.42 \pm 0.18$ & 1.327 & 0.049 \\
\hline
\end{tabular}

Values are presented as mean \pm standard deviation.

Table 5. Communication Competency in the Assessment of the Counselor's Role Viewpoint

\begin{tabular}{lcrrr}
\hline \multicolumn{1}{c}{ Variable } & Intervention group $(\mathrm{n}=22)$ & Control group $(\mathrm{n}=21)$ & $\mathrm{Z}$ & $\mathrm{p}$-value \\
\hline Interviewing evaluation from counselor's role viewpoint & & & & \\
Effectiveness of encouraging patient change & & & \\
$\quad$ Interviewing as helpful to patient & $3.93 \pm 0.42$ & $3.14 \pm 0.45$ & 2.214 & $<0.001$ \\
$\quad$ Interviewing of affecting patient & $3.93 \pm 0.39$ & $3.14 \pm 0.55$ & 2.058 & $<0.001$ \\
$\quad$ Total of patient change & $3.93 \pm 0.37$ & $3.14 \pm 0.47$ & 2.214 & $<0.001$ \\
Rapport establishment & & & \\
$\quad$ Re-interviewing intention & $4.02 \pm 0.33$ & $3.17 \pm 0.56$ & 2.341 & $<0.001$ \\
Patient's understanding of counselor's viewpoint & $4.02 \pm 0.19$ & $3.12 \pm 0.47$ & 2.817 & $<0.001$ \\
Counselor's understanding of patient's viewpoint & $3.98 \pm 0.29$ & $3.17 \pm 0.60$ & 2.029 & 0.001 \\
$\quad$ Total of Rapport establishment & $4.01 \pm 0.23$ & $3.15 \pm 0.46$ & 2.497 & $<0.001$ \\
Counselor competence and interest & & & & \\
$\quad$ Enjoyed the interview & $4.00 \pm 0.58$ & $3.21 \pm 0.68$ & 1.894 & 0.002 \\
$\quad$ Says skill use the technique & $3.68 \pm 0.85$ & $2.81 \pm 0.73$ & 1.916 & 0.001 \\
Confident and skilled in technique & $3.71 \pm 0.73$ & $2.57 \pm 0.69$ & 1.930 & 0.001 \\
Intention of use to motivational interviewing & $4.02 \pm 0.48$ & $3.05 \pm 0.67$ & 2.207 & $<0.001$ \\
$\quad$ Total of counselor competence & $3.85 \pm 0.57$ & $2.91 \pm 0.53$ & 2.377 & $<0.001$ \\
\hline
\end{tabular}

Values are presented as mean \pm standard deviation. 
measuring whether they had used a total of 5 skills, resulting in the final score of MI technique measurement. The results indicated that the intervention group $(1.83 \pm 0.19)$ had a higher score than the control group $(1.00 \pm 0.00)$, and these results were statistically significant. Among the sub-items of patient involvement evaluation, there were no statistically significant differences in "number of questions asked by patient" and "percentage time patient spent talking"; however, "patient suggested ways to change" was higher for the intervention group $(0.86 \pm 0.64)$ versus the control group $(0.19 \pm 0.29)$ with statistically significant differences. The rapport establishment between the individuals in counselor and patient roles was higher in the intervention group versus the control group, and the results were statistically significant.

\section{Interviewing competency evaluated from the role- play perspective}

The results were reviewed from the perspective of the counselor; the intervention group had higher competency scores than the control group and the results were statistically significant (Table 5). Details on encouraging patient change from the counselor perspective were composed of two factors of "Interviewing as helpful to patient" and "Interviewing of affecting patient"; in both factors, the intervention group $(3.93 \pm 0.37)$ had higher scores than the control group $(3.14 \pm 0.47)$ and the results were statistically significant. Details on the rapport establishment between the counselor and the patient were composed of "re-interviewing intention" (intervention group 4.02 \pm 0.33 , control group $3.17 \pm 0.56$ ), “patient's understanding of counselor's viewpoint" (intervention group 4.02 \pm 0.19 , control group $3.12 \pm 0.47$ ), and "counselor's understanding of patient's viewpoint" (intervention group $3.98 \pm 0.29$, control group $3.17 \pm 0.60$ ); overall rapport establishment was higher in the intervention group $(4.01 \pm 0.23)$ versus the control group $(3.15 \pm 0.46)$ with statistically significant differences. Details on the evaluation of counselor competence were divided into "enjoyed the interview" (intervention group 4.00 \pm 0.58 , control group 3.21 \pm 0.68 ), "interviewing expertise" (intervention group $3.68 \pm 0.85$, control group 2.81 \pm 0.73 ), "confidence in interviewing" (intervention group 3.71 \pm 0.73 , control group 2.57 \pm 0.69 ), and the "intention to use MI" (intervention group 4.02 \pm 0.48 , control group 3.05 \pm 0.67 ); overall, the counselor competence was higher in the intervention group $(3.85 \pm 0.57)$ versus the control group $(2.91 \pm 0.53)$ with statistically significant differences.

The evaluations from the patient role had higher scores for the intervention group versus the control group, and the results were statistically significant (Table 6). Details on encouraging change from the patient perspective were composed of "interviewing as helpful to patient" (intervention group $4.05 \pm 0.48$, control group $3.05 \pm 0.57$ ) and "interviewing of affecting patient" (intervention group $4.00 \pm 0.41$, control group $2.88 \pm 0.47$ ), and the overall effects

Table 6. Communication Competency in the Assessment of the Patient's Role Viewpoint

\begin{tabular}{|c|c|c|c|c|}
\hline Variable & Intervention group $(\mathrm{n}=22)$ & Control group $(n=21)$ & $\mathrm{Z}$ & p-value \\
\hline \multicolumn{5}{|l|}{ Interviewing evaluation from patient's role viewpoint } \\
\hline \multicolumn{5}{|l|}{ Effectiveness of encouraging patient change } \\
\hline Interviewing as helpful to patient & $4.05 \pm 0.48$ & $3.05 \pm 0.57$ & 2.192 & $<0.001$ \\
\hline Interviewing of affecting patient & $4.00 \pm 0.41$ & $2.88 \pm 0.47$ & 2.675 & $<0.001$ \\
\hline Total of patient change & $4.02 \pm 0.43$ & $2.96 \pm 0.44$ & 2.519 & $<0.001$ \\
\hline \multicolumn{5}{|l|}{ Rapport establishment } \\
\hline Re-interviewing intention & $4.14 \pm 0.49$ & $3.10 \pm 0.37$ & 2.675 & $<0.001$ \\
\hline Enjoyed the interview & $3.98 \pm 0.52$ & $2.89 \pm 0.50$ & 2.512 & $<0.001$ \\
\hline Patient's understanding of counselor's viewpoint & $4.14 \pm 0.52$ & $3.21 \pm 0.44$ & 2.363 & $<0.001$ \\
\hline Counselor's understanding of patient's viewpoint & $4.16 \pm 0.47$ & $3.17 \pm 0.48$ & 2.512 & $<0.001$ \\
\hline Total of Rapport establishment & $4.10 \pm 0.46$ & $3.09 \pm 0.34$ & 2.824 & $<0.001$ \\
\hline \multicolumn{5}{|l|}{ Counselor competence } \\
\hline Patient rated counselor as competent & $4.14 \pm 0.49$ & $2.86 \pm 0.42$ & 2.675 & $<0.001$ \\
\hline
\end{tabular}

Values are presented as mean \pm standard deviation. 
of encouraging change was higher in the intervention group (4.02 \pm 0.43$)$ versus the control group $(2.96 \pm 0.44)$ with statistically significant differences. The evaluation of rapport establishment was higher in the intervention group $(4.10 \pm 0.46)$ than the control group $(3.09 \pm 0.34)$ with statistically significant differences. The factors included "re-interviewing intention" (intervention group 4.14 \pm 0.49 , control group 3.10 \pm 0.37 ), "enjoyed the interview" (intervention group 3.98 \pm 0.52 , control group 2.89 \pm 0.50 ), "patient's understanding of counselor's viewpoint" (intervention group $4.14 \pm 0.52$, control group $3.21 \pm 0.44$ ), and "counselor's understanding of patient's viewpoint" (intervention group $4.16 \pm 0.47$, control group $3.17 \pm 0.48$ ), and the intervention group had higher scores in all factors. To assess the competency of the counselor role, the satisfaction of techniques and attitudes of the counselor were measured; the results of the analysis indicated that the satisfaction was higher for the intervention group $(4.14 \pm 0.49)$ than the control group $(2.86 \pm 0.42)$ with statistically significant differences.

\section{Discussion}

This study has applied the MI theory to develop and apply an interview training program for dental hygiene students to evaluate the effectiveness of the program. The MI training program applied in this study is a program that reflects key theories based on basic MI principles, and was developed by collecting new strategies. The results of existing studies, recommending that communication and interview programs should be coupled with theory lectures and practice for effectiveness 5,17,19-21), support the strategy of this study. As such, this study has provided a number of cases as an indirect practice, and included methods of 2-person group partner practice and 3-person small group discussion and role-play as strategies. Simulation learning has the advantage of recreating real-life scenarios resembling clinical situations in a safe environment, thus increasing the task skills. Moreover, in the field of communication, standardized patients and role-play are used to assume certain situations for learning purposes; the application of immediate, simulated field practice right after theory learning is known to be effective ${ }^{20)}$. Lane and
Rollnick $^{17)}$ and Rollnick et al. ${ }^{13)}$, who organized and reported on literature covering standardized patients and role-play, mentioned that standardized patients and role-play that create hypothetical situations are effective for the improvement in communication competency, and recommended role-play to supplement the limitations of time in practices using standardized patients. As such, the situations created by role-play in this study have been formed to fit the specific situations in Korea by referring to cases covering patient strategies for motivation enhancement, and role-play training was based on scenarios that are commonly faced in dental clinics and hospitals. The content of the program covered the brief MI strategy based on the basic principles of MI, which could be easily used in the clinical field. Rollnick et al. ${ }^{13)}$ reported on the need for a strategy that included 5- to 15-minute focused interviews, as patients have a unique level of readiness for change and may respond sensitively. Particularly, patients visiting dental hospitals or clinics tend to visit for the purposes of treatment, rather than of behavioral change, unlike patients visiting other medical facilities. As the goal sought by the patient is firm, it is realistically impossible to conduct counseling for a period of over 50 minutes. Therefore, this study had also set an interview situation through short sessions, thus sessions could be used in clinical settings as well as resolve the objective of the patient. While role-play is heavily influential in communication education, there are no systematic factors or methods in evaluating standardized patient or role-play practices ${ }^{17)}$. Therefore, it appeared necessary to develop tools that could be used by the learners and educators in communication practice.

To evaluate the effectiveness of the MI training program, 43 study participants were recruited. The participants were fourth-year college students enrolled in the dental hygiene department at a college in Cheonan, and they were randomly assigned to the intervention group and control group depending on the order of their recruitment. This study assessed communication competence after the implementation of the program; the intervention group with education had higher scores in MI skills and competence. In the MI training technique competency, both groups had a high ratio of employing 
the "set the agenda" skill, with no differences between groups. The reason why this skill was widely employed appears to be due to the fact that participants are in their fourth year of dental hygiene, having taken classes in communication and public health, which made it easier for them to employ the skill. The extent of using "open-ended questions," "brief MI techniques," as well as "patient suggested ways to change" and "rapport establishment" was higher in the intervention group with education, and they also had higher scores than the control group in competency evaluations of counselor and patient roles. These results were in line with studies by Spollen et al. ${ }^{8)}$, applying the MI program to medical students, and Koerber et al. ${ }^{7)}$, applying the program to students in dentistry, both reporting that intervention groups showed higher competence. This study has confirmed the need for efforts such as interview education and program participation to raise communication competence, supported by studies reporting positive results of program intervention.

The principle of inducing behavioral change by increasing the percentage of change talks has been emphasized in MI; Croffoot et al. ${ }^{22)}$, who also reported better results in behavioral commitment and inducing change talks in dental hygiene students with MI training. Their results are similar to those of this study, as the intervention group was found to induce more ways to change for the patient, as well as to ask more open-ended questions. DeBate et al. ${ }^{23)}$ confirmed the improvements in knowledge, techniques, and self-efficacy through a MI training workshop for college students in dentistry and dental hygiene; Choi et al. ${ }^{5)}$ reported that college students who have learned communication embrace it as a basic vocational skill and attitude that can improve their career and professionalism. Thus, one is able to conclude that one-time interview education and training aids in improving communication competence, and ongoing training as well as expert and peer feedback would help to gradually increase such competence, while unseen. The application of NCS in college systems has led to the need for varying curricula such as communication, patient management and psychology in dental hygiene, similar to other educational programs for national certifications.

This study has several limitations. Given the lack in the nature of related fields and the realistic differences between the clinical situations and educational institutions, the MI training program utilized in this study would not present long-term educational effects. This should be supplemented by future studies on the effects of MI training as well as varying methods of education. Moreover, this study has utilized measurement tools that involve the self-evaluation by participants and analysis by the researcher. This may be influenced by subjective opinions. Therefore, it is necessary to develop a measurement tool that can be applied in the clinical situation in the field of MI.

\section{References}

1. Human Resources Development Service of Korea: Standard development of vocational competency, 2004. HRD Korea Publishing, Seoul, pp.13-14, 2014.

2. ADEA Competencies for entry into the allied dental professions: (as approved by the 2011 ADEA House of Delegates). J Dent Educ 81: 853-860, 2017.

3. Commission on Dental Accreditation: Accreditation standards for dental hygiene education programs. ADA, Chicago, pp.12-28, 2016.

4. Ryu DY, Yang HS, Choi YK: Needs and perception of medical communication course in the dental hygiene students. J Korean Soc Dent Hyg 14: 623-630, 2014. https://doi.org/10.13065/jksdh.2014.14.05.623

5. Choi YK, Shin BM, Son JH, Park DY: Effectiveness and learning experience of dental communication course training in dental hygiene schools. J Dent Hyg Sci 16: 134-141, 2016. https://doi.org/10.17135/jdhs.2016.16.2.134

6. Bazata DD, Robinson JG, Fox KM, Grandy S; SHIELD Study Group: Affecting behavior change in individuals with diabetes: findings from the Study to Help Improve Early Evaluation and Management of Risk Factors Leading to Diabetes (SHIELD). Diabetes Educ Dec 34: 1025-1036, 2008. https://doi.org/10.1177/0145721708325767

7. Koerber A, Crawford J, O'Connell K: The effects of teaching dental students brief motivational interviewing for smoking-cessation counseling: a pilot study. J Dent Educ 67: 439-447, 2003.

8. Spollen JJ, Thrush CR, Mui DV, Woods MB, Tariq SG, 
Hicks E: A randomized controlled trial of behavior change counseling education for medical students. Med Teach 32: e170-e177, 2010. https://doi.org/10.3109/01421590903514614

9. Curry-Chiu ME, Catley D, Voelker MA, Bray KK: Dental hygienists' experiences with motivational interviewing: a qualitative study. J Dent Educ 79: 897-906, 2015.

10. Woelber JP, Spann-Aloge N, Hanna G, et al.: Training of dental professionals in motivational interviewing can heighten interdental cleaning self-efficacy in periodontal patients. Front Psychol 7: 254, 2016. https://doi.org/10.3389/fpsyg.2016.00254

11. Miller WR, Rollnick S: Meeting in the middle: motivational interviewing and self-determination theory. Int J Behav Nutr Phys Act 9: 25, 2012. https://doi.org/10.1186/1479-5868-9-25

12. Miller WR, Rollnick S, Moyers TB: Motivational interviewing: helping people change. 3rd ed. Guilford Press, New York, 2013. 211 p.

13. Rollnick S, Heather N, Bell A: Negotiating behaviour change in medical settings: the development of brief motivational interviewing. J Ment Health 1: 25-37, 2009. https://doi.org/10.3109/09638239209034509

14. Darby ML, Walsh MM: Dental hygiene: theory and practice. 3rd ed. Saunders Elsevier, St. Louis, pp.37-55, 2010.

15. Wilkins EM: Clinical practice of the dental hygienist. 12th ed. Wolters Kluwer, Philadelphia, pp.419-434, 2017.

16. Hinz JG: Teaching dental students motivational interviewing techniques: analysis of a third-year class assignment. J Dent Educ 74: 1351-1356, 2010.
17. Lane C, Rollnick S: The use of simulated patients and role-play in communication skills training: a review of the literature to August 2005. Patient Educ Couns 67: 13-20, 2007. https://doi.org/10.1016/j.pec.2007.02.011

18. White LL, Gazewood JD, Mounsey AL: Teaching students behavior change skills: description and assessment of a new Motivational interviewing curriculum. Med Teach 29: e67-e71, 2007. https://doi.org/10.1080/01421590601032443

19. Bae SH, Park JS: Development and evaluation of extracurricular coaching programs for improving communication skills and leadership among nursing students. J Korean Acad Soc Nurs Educ 21: 202-214, 2015. https://doi.org/10.5977/jkasne.2015.21.2.202

20. Kim SJ, Kim HH: Impact of communication competence and empathy abilities on interpersonal relationship abilities among dental hygiene students. J Dent Hyg Sci 13: 304-313, 2013.

21. Chung SH: A study of the TA program and its effects on the development of communication skills for dental hygienist. J Dent Hyg Sci 6: 295-302, 2006

22. Croffoot C, Krust Bray K, Black MA, Koerber A: Evaluating the effects of coaching to improve motivational interviewing skills of dental hygiene students. J Dent Hyg 84: 57-64, 2010.

23. DeBate RD, Cragun D, Gallentine AA, et al.: Evaluate, assess, treat: development and evaluation of the EAT framework to increase effective communication regarding sensitive oral-systemic health issues. Eur J Dent Educ 16: 232-238, 2012.

https://doi.org/10.1111/j.1600-0579.2012.00747.x 